
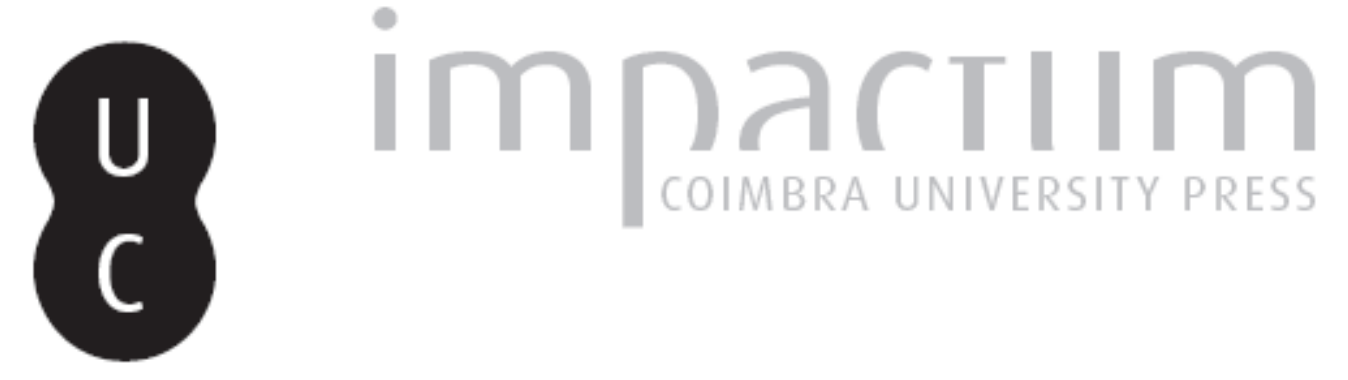
[Recensão a] Murat, Laure (2013), L'homme qui se prenait pour Napoléon. Pour une
histoire politique de la folie

Autor(es): $\quad$ Ferreira, Tânia Sofia

Publicado por: Imprensa da Universidade de Coimbra

URL persistente:

URI:http://hdl.handle.net/10316.2/43349

DOI:

DOI:https://doi.org/10.14195/1645-2259_17_24

Accessed : $\quad$ 26-Apr-2023 12:09:40

A navegação consulta e descarregamento dos títulos inseridos nas Bibliotecas Digitais UC Digitalis, UC Pombalina e UC Impactum, pressupõem a aceitação plena e sem reservas dos Termos e Condições de Uso destas Bibliotecas Digitais, disponíveis em https://digitalis.uc.pt/pt-pt/termos.

Conforme exposto nos referidos Termos e Condições de Uso, o descarregamento de títulos de acesso restrito requer uma licença válida de autorização devendo o utilizador aceder ao(s) documento(s) a partir de um endereço de IP da instituição detentora da supramencionada licença.

Ao utilizador é apenas permitido o descarregamento para uso pessoal, pelo que o emprego do(s) título(s) descarregado(s) para outro fim, designadamente comercial, carece de autorização do respetivo autor ou editor da obra.

Na medida em que todas as obras da UC Digitalis se encontram protegidas pelo Código do Direito de Autor e Direitos Conexos e demais legislação aplicável, toda a cópia, parcial ou total, deste documento, nos casos em que é legalmente admitida, deverá conter ou fazer-se acompanhar por este aviso.

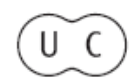




\section{Murat, Laure (2013), L'homme qui se prenait pour Napoléon. Pour une histoire politique de la folie, Folio, 432 pp., ISBN 978- 2-07-044835-7.}

Qual o impacto dos acontecimentos históricos sob loucura? Podemos avaliar o papel de uma revolução ou de uma mudança de regime na evolução do discurso da desrazão? Que inquietudes políticas e sociais os delírios comportam? Para responder a estas questões, Laure Murat interrogou os arquivos psiquiátricos dos grandes asilos de alienados do século XIX: Bicêtre, La Salpêtrière, Sainte-Anne e Charenton, num período compreendido entre 1789 a 1871.

No primeiro capítulo, 1793 ou comment perdre la tête, Laure Murat observa que, sobretudo sob o Terror, há uma relação evidente entre o nascimento da psiquiatria e a invenção da guilhotina, como sugere o duplo sentido da expressão «perder a cabeça». Deste modo, a "psiquiatria e a guilhotina unem-se na relação da cabeça e do corpo, da sua ligação ou do seu divórcio, da integridade do eu e da consciência" (p. 63). As duas foram concebidas pelo corpo médico e ambas respondiam ao mesmo projecto político que visava reformar a sociedade. Em Spectres de la guillotine, a autora evidencia o poder que a imagem da guilhotina teve na assombração das consciências. Como nota Laure Murat, "a figura da «cabeça cortada» teve o poder de "petrificar", tanto que nos asilos «o terror tem um rosto: a guilhotina $\gg$ (p. 101).

No entender da autora, com a Revolução e a investida científica de Pinel, a psiquiatria torna-se uma significante arma ao serviço do Estado. Em Un médecin au chevet du corpos de l'État, a investigadora realça a proximidade do discurso psiquiátrico com o discurso político, onde o primeiro surge como uma instância de legitimação do segundo, ao mesmo tempo que explora as contradições do tratamento moral preconizado pelo pai da psiquiatria francesa.

No segundo capítulo, L'asile, prison politique, Laure Murat constata que sob o Terror, o poder político mantinha "um estranho casamento entre alienação e repressão", ao requisitar estabelecimentos de cuidados privados para os transformar em prisões. Assim, para a autora instalou-se neste período uma "tripla confusão" fruto da interseção entre a psiquiatria e o poder político: "confusão de estatuto entre casa de saúde e casa de detenção (Belhome...), confusão de natureza entre o louco e o opositor ao regime (Malet); confusão de papéis do alienista, que coopera com o poder, mas protege também os detidos que lhe são confiados (Dubuisson, Casimir Pinel) (p. 137).

Sem procurar questionar a hipotética realidade da doença mental, mas no esforço por "esclarecer os critérios de internamento e o sistema complexo que os ordena" Laure Murat esmiuça no subcapítulo Dissidence ou démence?, a ambi- 
guidade dos "casos médicos" referentes ao político. A partir de que momento e segundo que critérios "nos afastamos de um discurso político 'razoável" e a partir de que momento e segundo que critérios "a dissidência se acompanha de excessos considerados 'delirantes'?'

No terceiro capítulo, L’homme qui se prenait pour Napoléon, Laure Murat refere que, no dia seguinte ao retorno das cinzas de Napoleão, a 15 de dezembro de 1840, o director de Bicêtre assinala a entrada de quatorze novos "imperadores".

Como explica a autora, o século XIX conhece uma doença específica chamada monomania dita "orgulhosa" ou "ambiciosa", contemporânea de uma certa "heroicização do mundo", que segundo a autora deve muito à figura de Napoleão Bonaparte. Responde também aos anseios de uma sociedade preocupada com a glória individual e que assiste a uma "exaltação do eu" sem precedentes. Neste contexto, para o Dr. François Fabre, não há dúvida de que "a loucura do século é o orgulho" e jamais na história "vimos tantos homens dar-se por sábios, capacitados, talentosos de primeira ordem” (p. 188).

Napoleão é o maître de l'univers, é a "figura por excelência do super-homem, o símbolo próprio da dominação e de todo o poder moderno" (p. 217). Face a outros reis europeus, cujos títulos eram herdados através de longas dinastias de direito divino, Napoleão é o Usurpador que chega à cabeça da Europa por ele próprio. O exemplo compara-se ao que os Estados Unidos chamam de um self-made-man. Neste âmbito, é fácil supor que a projecção de um monarca conquistador tenha catalizado os delírios de centenas de homens e mulheres, "frequentemente frágeis pela existência", e que são uma dia autorizados a identificar-se com Napoleão, esse "prodigioso fenómeno de vontade". Através da sua imagem de conquistador, seguro de que o "impossivel não é francês", o poder torna-se acessível a todo aquele que desejava fundar uma nova dinastia e mudar o mundo (p. 219).

No quarto capítulo, Morbus democraticus, Laure Murat nota que a grande maioria dos alienistas do século XIX estigmatizou a exaltação republicana e os seus efeitos nas populações. Os médicos veem-se confrontados, neste período, com um aumento de alienados nos asilos e desta forma "tentam racionalizar e por em palavras de especialista estes desejos de emancipação, de liberdade e de progresso" (p. 242). Como explica a autora, assistimos a uma "psiquiatrização crescente do político", com a aparição de termos como monomania política, depois morbus democraticus (doença democrática) ou ainda "paranóia reformadora", para designar a "epidemia" da época.

No subcapítulo Théroigne de Méricourt ou la melancolie révolutionnaire, a autora apresenta-nos o célebre caso desta jovem revolucionária, estudo clássico elaborado por Esquirol, da "lipemania" ou melancolia. O dossier que o médico fará da sua paciente é, no entender da autora, a prova da deturpação de um 
diagnóstico com base nas convicções políticas e morais do alienista. Para Laure Murat este caso ilustra bem a manipulação e a construção de um diagnóstico, onde Esquirol "muda os factos, e sobretudo interpreta-os, para demonstrar 'clinicamente' os danos supostos da Revolução" (p. 256).

No subcapítulo L'Asile de la misère, a autora foca o papel das condições de vida do século XIX enquanto potenciadoras da alienação mental, onde o asilo surge como o espelho de uma sociedade atingida por "um dos grandes flagelos do século: a miséria". Neste âmbito, o delírio entende-se como um "refúgio que tem propriedade de consolação". Os mais miseráveis veem-se subitamente duques e duquesas, reis e rainhas, milionários e donos do mundo; a loucura constituiu para muitas destas pessoas "a última defesa contra o horror de um destino sem saída" (p. 318).

No quinto capítulo, La Raison Insurgée, Laure Murat explora as consequências que vários conflitos bélicos do século XIX tiveram na produção dos delírios. Em Jeanne D'Arcc et les panaphofes gémisseurs a autora nota que muitas mulheres acreditavam ser Jean d'Arc, cujo processo de canonização começava em 1869, e portanto, as "heroínas de França” que "Deus lhes impôs a tarefa de salvar o país" (p. 333).

Esta obra revela-se de leitura importante sob diversos aspetos. Em primeiro lugar pelo carácter inédito do seu sujeito: $\mathrm{o}$ alienado. Laure Murat demonstra ao longo deste livro que o discurso da desrazão tem muito a dizer sobre os grandes acontecimentos políticos, económicos e sociais do século XIX. Os discursos da desrazão, desvalorizados durante muito tempo, escondidos atrás do discurso paradigmático do alienista, dão-nos pistas importantes sobre os medos, as inquietudes, as ansiedades de uma sociedade que assistiu ao conturbado nascimento do mundo contemporâneo. Esta obra, ao explorar o contexto em que foram moldados os alienistas e as suas obras, constitui um indispensável apoio à investigação para todos os que tencionem estudar matérias relacionadas com o desenvolvimento da psiquiatria e os alienistas portugueses, já que todo o corpo científico do alienismo foi forjado precisamente no período que Laure Murat balizou nesta obra.

TÂNIA SOFIA Ferreira 